\title{
Detección de Chlamydia trachomatis en hombres que tienen sexo con hombres en Bogotá: un estudio piloto
}

\author{
Detection of chlamydia trachomatis in men that have sex with men \\ in Bogotá: a pilot study
}

Fredy Alberto Rodríguez Rojas ${ }^{1,2}$, Paula Steffany Barreto Ordoñez ${ }^{2}$, Ruth Mélida Sánchez Mora ${ }^{3}$.

\section{Resumen}

Objetivo. Optimizar una técnica PCR que permita evaluar la presencia de C. trachomatis en hisopados anorrectales provenientes de $\mathrm{HSH}$. En Colombia se notifican anualmente más de 70.000 casos nuevos de ITS, de los cuales se estima que aproximadamente el 9.3\% corresponde a uretritis entre las que se encuentran las causadas por $C$. trachomatis. Métodos. Uno de los problemas en el método de detección de $C$. trachomatis por PCR en muestras de hisopado anorrectal es la extracción de ADN, el uso de equipos automatizados dispuestos en el mercado resulta costoso y en muchos de los casos no están disponibles en el laboratorio clínico de rutina. En este estudio se realizó una PCR para detección de $C$. trachomatis, estableciendo un protocolo para la toma de muestra y extracción de $\mathrm{ADN}$ a partir de hisopos anorrectales. Resultados. Se procesaron 27 muestras correspondientes a HSH voluntarios pertenecientes al Grupo de apoyo y estudio de la Diversidad Sexual (GAEDS) de la Universidad Nacional de Colombia. Se encontraron 5 muestras positivas para $C$. trachomatis en hombres sintomáticos y asintomáticos relacionado con el riesgo de adquirir infección por sus prácticas sexuales.

Palabras clave: Chlamydia trachomatis, hombres que tienen sexo con hombres (HSH), Sexo anal, reacción en cadena de la polimerasa (PCR), factor de riesgo, infecciones de transmisión sexual (ITS)

\section{Abstract}

Objective. optimize a PCR technique to evaluate the presence of C. trachomatis in anorectal swabs from MSM. In Colombia there are reported each year more than 70,000 new cases of STIs, of which it is estimated that approximately $9.3 \%$ is urethritis among which are those caused by C. trachomatis. Methods. DNA extraction is one of the problems in the method of detecting $C$. trachomatis by PCR anorectal swab samples. Besides, the use of automated equipment arranged on the market is expensive and in many cases the samples are not available in the clinical laboratory routine. In this study it was performed PCR for detection of C. trachomatis protocol establishing the sampling and DNA extraction from anorectal swabs. Results. 27 samples were

\footnotetext{
Bacteriólogo - Joven investigador. Universidad Colegio Mayor de Cundinamarca. - ORCID: 0000-0002-3566-0813

Bacterióloga Universidad Colegio Mayor de Cundinamarca. - ORCID: 0000-0002-9607-8608

Docente Universidad Colegio Mayor de Cundinamarca. PhD Biotecnología. MSc Genética Humana. - ORCID: 0000-0002-0572-8418

Institución en donde se llevó acabo el trabajo: Universidad Colegio Mayor de Cundinamarca - Grupo de Biotecnología y Genética, UCMC

Correspondencia: rmsanchezm@unicolmayor.edu.com

Fecha de recepción: Junio 27 de 2016 - Fecha de aprobación: Octubre 18 de 2016
} 
processed corresponding HSH volunteers belonging to the Support group and study of Sexual Diversity (GAEDS) of the National University of Colombia. 5 samples positive for $C$. trachomatis associated with both symptomatic and asymptomatic men at high risk of acquiring infection because of their sexual practices were found.

Key words: Chlamydia trachomatis, Men Who have Sex with Men (MSM), Anal Sex, PCR, Risk Factors, Sexual Transmission Infections (STI).

\section{Introducción}

La infección ocasionada por $C$. trachomatis es la causa más frecuente de ITS que puede ser tratada en el ser humano. La OMS estimó que para el año 2005 se presentaron cerca de 98 millones de casos nuevos a nivel mundial, de los cuales cerca de 39 millones ocurrieron en hombres. Además, en el año 2008 se presentó un aumento en la incidencia de la infección del 4.1\% (105.7 millones de casos) con respecto al año 2005 (101.5 millones de casos), (1). En países como Estados Unidos y el Reino Unido se reporta 4.5 millones de casos anualmente por C. trachomatis. Los costos directos e indirectos generados por la infección con este microorganismo son muy altos debido a las consecuencias y secuelas generadas, principalmente, la enfermedad pélvica inflamatoria en mujeres y el linfogranuloma venéreo (LGV) en hombres. C. trachomatis se clasifica por la proteína mayor de membrana externa (MOMP) en diferentes serotipos, entre los cuales L1, L2, L2a, L2b y L3 afectan a los HSH siendo el agente causal de LGV (2).

En Colombia se realizan estudios de incidencia y prevalencia en mujeres con infecciones causadas por C. trachomatis desde el año de 1995 (3). Sin embargo, no se han descritos datos epidemiológicos de la infección causada en la población de hombres y tampoco existen estudios en los que se muestre la presencia de este patógeno en la población HSH. Por otro lado, siendo $C$. trachomatis y $N$. gonorrhoeae las ITS de mayor transmisión (4), en Colombia no existen centros especializados para el diagnóstico de estos patógenos como existe en otros países.
Las infecciones por C. trachomatis son asintomáticas en el $70 \%$ de las mujeres y el $40 \%$ de los hombres, lo que dificulta el diagnóstico en las fases tempranas de la infección y el tratamiento oportuno, lo que conlleva a un aumento en los contagios en la población (3). Por otro lado, actualmente los servicios de salud no poseen un protocolo de diagnóstico ni un esquema claro de prevención en cuanto a las infecciones por $C$. trachomatis en poblaciones vulnerable como los $\mathrm{HSH}$, por lo que no se cuenta con datos exactos de la prevalencia de este microorganismo en la población colombiana. Un estudio realizado en Colombia (2013) en estudiantes de 14 a 19 años de edad sexualmente activos, a partir de muestras de orina, mostró una prevalencia de C. trachomatis del 2.24\%. De estos casos el $21.4 \%$ correspondieron a mujeres asintomáticas; además, el 34,1\% de los hombres y el $79 \%$ de las mujeres con $C$. trachomatis o $N$. gonorrhoeae informó haber padecido al menos un síntoma de ITS en los últimos 3 meses (5).

Ante el crecimiento global de la infección por este microorganismo, el Center for Disease Control and Prevention (CDC) desarrolló un programa de tamizaje para el diagnóstico de VIH y otras ITS, entre las que se encuentra $C$. trachomatis. En este programa anualmente se realiza cultivo de $C$. trachomatis y $N$. gonorrhoeae a partir de muestras uretrales y de orina en $\mathrm{HSH}$ y practican sexo anal receptivo; recomendando un tamizaje cada 3-6 meses en esta población, que es considerada de alto riesgo, debido a sus prácticas sexuales y al curso asintomático de la infección. A pesar de que existen varios métodos de diagnóstico para detectar $C$. 
trachomatis, actualmente las pruebas de detección de ITS rectal no son una opción generalizada (3-6).

En Colombia no existen estadísticas de morbilidad, prevalencia o incidencia de la infección por C. trachomatis en la población de hombres y $\mathrm{HSH}$, porque no se dispone de programas de tamizaje. Se han realizado estudios enfocados principalmente en demostrar cómo la infección por este microorganismo afecta el tracto genital femenino, mientras que en hombres a pesar de que actúan como transmisores de la infección, no se han realizado estudios similares.

En este estudio se optimizó una técnica PCR que permitió evaluar la presencia de $C$. trachomatis en hisopados anorrectales provenientes de $27 \mathrm{HSH}$ que pertenecen al grupo GAEDS de la Universidad Nacional de Colombia, con el fin de poder evaluar a futuro la prevalencia de este microorganismo en poblaciones donde se desconocen estos datos epidemiológicos, lo que permitiría disminuir el riesgo de adquirir el contagio por VIH/SIDA y otras patologías de importancia que se han visto relacionadas con este tipo de infección.

\section{Metodología}

Se realizó un estudio de tipo descriptivo con orientación transversal, en $27 \mathrm{HSH}$ voluntarios pertenecientes al grupo GAEDS. Las edades de los participantes oscilaban entre los 18 y 30 años, los cuales cumplieron con los criterios de inclusión y exclusión establecidos inicialmente, Tabla 1 . Se contó con la aprobación del comité de bioética de la Universidad Colegio Mayor de Cundinamarca.

Inicialmente, se llevó a cabo una sesión informativa donde se dio a conocer la problemática y los objetivos propuestos en el estudio. Los participantes interesados firmaron el consentimiento informado y diligenciaron una encuesta cerrada de tipo descriptivo, la cual incluyó preguntas socio-demográficas acerca de los factores y riesgos asociados a la conducta sexual, consumo de alcohol y sustancias alucinógenas, y percepción de riesgo. También se incluyó una sesión con preguntas de conocimientos generales acerca de salud sexual e ITS. La encuesta fue valorada en una escala de 1 a 5 . Finalmente, cada participante recibió un folleto con las indicaciones para la toma de la auto-muestra.

Tabla 1. Criterios de inclusión y exclusión utilizados para la selección de los HSH participantes en el estudio

\begin{tabular}{ll}
\hline \multicolumn{1}{c}{ Inclusión } & \\
\hline \multicolumn{1}{|c}{ CRITERIOS } & \multicolumn{1}{c}{ Exclusión } \\
\hline - Ser mayor de 18 ańos y menor de 30 ańos. & - Ser menor de 18 ańos y mayor de 30. \\
- Haber iniciado una vida sexual. & - No haber iniciado una vida sexual. \\
- Ser homosexual. & - Ser heterosexual o bisexual. \\
- Tener un vida sexual activa. & - No haber tenido relaciones sexuales en el último año. \\
- No haber tomado antibióticos en los últimos 3 meses. & - Estar medicado con antibióticos. \\
- Que practique sexo anal insertivo y/o receptivo. & - Que no practique sexo anal. \\
\hline
\end{tabular}

\section{Toma de muestra}

La muestra de hisopado anorrectal fue tomada por cada uno de los participantes, quienes debían colocar un hisopo de dacrón a una profundidad de $2-4 \mathrm{~cm}$ del esfínter anal, con el fin de tomar muestra de las criptas anales, por medio de la rotación del hisopo. Las muestras fueron transportadas en medio SDS/PBS; aquellas que no fueron procesadas en las primeras 48 horas fueron conservadas $\mathrm{a}-20^{\circ} \mathrm{C} \mathrm{o} \mathrm{a}-70^{\circ} \mathrm{C}$.

\section{Optimización de la extracción de ADN}

Para optimizar la extracción de ADN de los hisopados anorrectales, dos participantes aportaron muestras por duplicado, estas fueron transportadas en PBS 1X y un medio de transporte a base SDS 


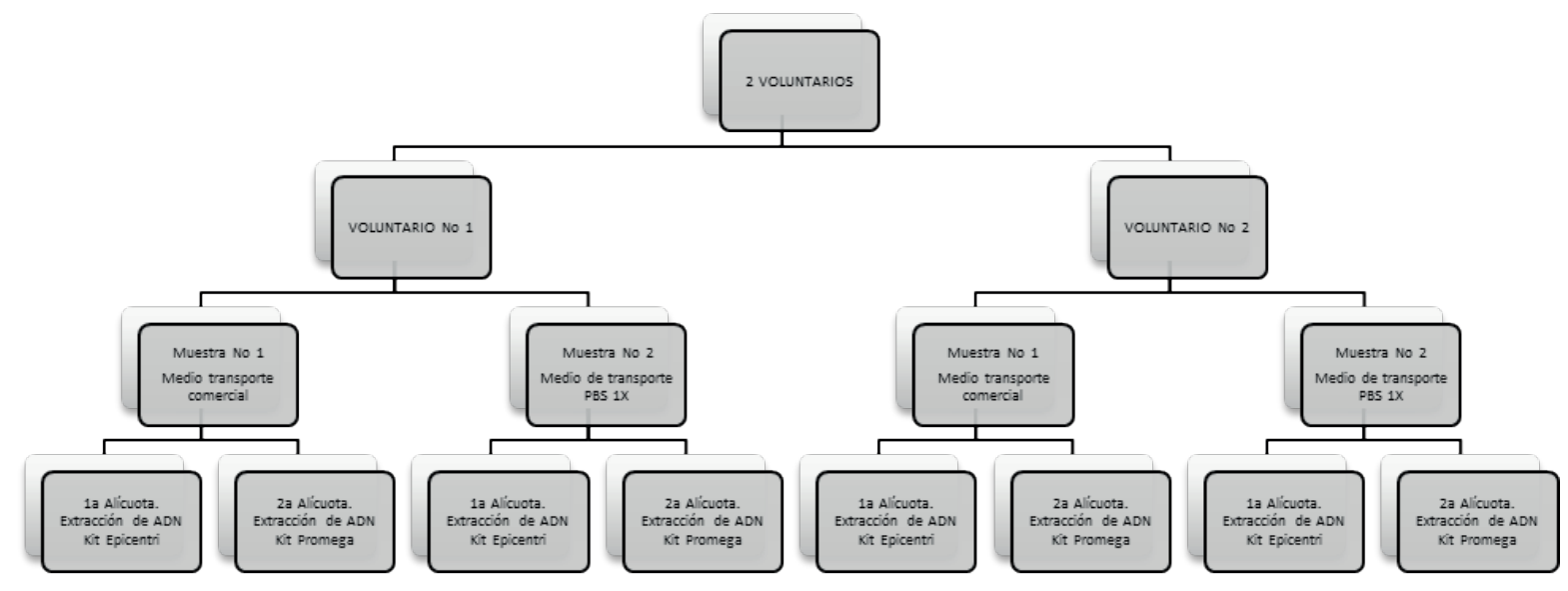

Figura 1. Esquema para la optimización de la extracción de ADN: Distribución de las dos muestras donadas por dos voluntarios y usadas para la extracción de ADN utilizando un medio de transporte donado por una casa comercial y PBS $1 \mathrm{X}$. Extracion con el kits de las casas comerciales de Promega y Epicentre.

(Sodium Dodecyl Sulfate) donado por una casa comercial. Inicialmente se les realizó un pre tratamiento que consistió en 5 lavados utilizando PBS 1X filtrado, durante 5 minutos a $13000 \mathrm{~g}$ entre lavado y lavado, con la finalidad de disminuir la presencia de sales biliares. Seguido de los lavados se realizó la extracción de ADN siguiendo las instrucciones dadas por las casas comerciales Promega y Epicentre respectivamente, Figura 3.

Una vez optimizada la extracción de ADN de los dos voluntarios, se recolectaron las 27 muestras de los participantes en PBS 1X y se realizó el pretratamiento y la extracción de ADN con el kit de la casa comercial Promega. Posteriormente las muestras fueron sometidas a la determinación de B-globina para evaluar la celularidad y eficiencia en la toma de la muestra.

\section{Determinación de B-globina}

Para evaluar la celularidad de las muestras de hisopados anorrectales se realizó la amplificación de un fragmento del gen de la proteína B-globina humana utilizando los primers comerciales GH20 y PCO4, con los que se obtiene un producto de amplificación de $230 \mathrm{pb}$. El proceso de amplificación inició con 5 minutos de desnaturalización a $95^{\circ} \mathrm{C}$ y 35 ciclos de amplificación. Cada ciclo consistió en desnaturalización a $95^{\circ} \mathrm{C}$ durante 1 minuto, hibridación a $58^{\circ} \mathrm{C}$ durante 1 minuto y la elongación a $72^{\circ} \mathrm{C}$ durante 1 minuto. Los productos de la PCR se visualizaron en geles de agarosa al $1.5 \%$, utilizando un patrón de peso molecular (PCR Hyperlander II) con un rango de $50 \mathrm{a} 2000 \mathrm{pb}$ y buffer TAE $1 \mathrm{X}$ para el corrido electroforético. Los geles fueron teñidos con SYBR Green y visualizados posteriormente en un trans-iluminador ultravioleta. Como control se utilizó ADN extraído de sangre total; se consideró que una muestra fue tomada correctamente al evidenciar la amplificación del fragmento de $230 \mathrm{pb}$ para B-globina.

\section{Detección de C. trachomatis}

Para la detección de $C$. trachomatis en las muestras anorrectales se utilizó como control positivo ADN extraído previamente en un estudio realizado en la Fundación Instituto de Inmunología de Colombia (FIDIC). Se usaron los sets de primer CTP 1-2 que amplifican un fragmento del $201 \mathrm{pb}$ y CTR12 que amplifican un producto de $310 \mathrm{pb}$, siendo este último más inespecífico para $C$. trachomatis. Como control negativo se utilizó ADN de Escherichia coli ATCC 35218. El protocolo de amplificación y visualización de los productos de la PCR se realizaron bajo las mismas condiciones empleadas para B-globina. 


\section{Resultados}

En este estudio participaron $27 \mathrm{HSH}$ del grupo GAEDS. Los participantes declararon ser sexualmente activos en el momento del estudio y con edades entre los 18 y 30 años (promedio 22.10 años; de 2.8 años). En promedio iniciaron su vida sexual a los 15,37 años y en los últimos 3 meses han sostenido relaciones con aproximadamente 3 personas, Tabla 2 .

\section{Determinantes de riesgo para infecciones con $C$. trachomatis en $\mathrm{HSH}$}

Los determinantes de riesgos asociados a las prácticas sexuales fueron en su orden: sexo anal insertivo el $96.2 \%$, el $66.6 \%$ admitió que alguna vez había consumido bebidas alcohólicas o drogas durante sus relaciones sexuales y el $44,4 \%$ no haber utilizado preservativo. En cuanto a la auto-calificación de los

Tabla 2. Descripción de la población: Características de la población de HSH participantes en el estudio

\begin{tabular}{|c|c|c|c|}
\hline \multicolumn{2}{|c|}{ EDAD } & t & $\neq$ \\
\hline Mínimo & 18,0 & 7,0 & 0,0 \\
\hline $25 \%$ Percentiles & 20,0 & 14,0 & 1,0 \\
\hline Mediana & 22,0 & 16,0 & 2,0 \\
\hline 75\% Percentiles & 24,0 & 18,0 & 4,0 \\
\hline Máximo & 30,0 & 19,0 & 6,0 \\
\hline Media & 22,10 & 15,37 & 2,77 \\
\hline IC 95\% & $20,9-23,2$ & $14,3-16,4$ & $2,0-3,4$ \\
\hline Desviación Estándar & 2,85998 & 2,70538 & 1,76141 \\
\hline Error Estándar & 0,550403 & 0,520651 & 0,338933 \\
\hline
\end{tabular}

participantes frente a contraer una ITS, el 92.58\% se ubicó en los riesgos más bajo, Figura 1.

Dentro de los datos obtenidos en los determinantes de riesgo asociado al comportamiento sexual, el $55 \%$ de los participantes manifestaron tener una relación vigente. El conocimiento por parte de los participantes acerca de C. trachomatis fue del 55\%; sin embargo, solo el $37 \%$ informó conocer alguna de las patologías causadas por el microorganismo. El 33.3\% de los participantes declararon haber sostenido relaciones sexuales durante lo que lleva de su vida sexual activa con un promedio de 6 a 10 personas, Figura 2.

Optimización de la extracción de ADN de las muestras de hisopado anorrectal

La optimización de la extracción de ADN de los hisopados anorrectales se observa en la figura 4 .
La presencia de ADN se observó utilizando el medio de transporte de PBS 1X y el kit de la casa comercial Promega, Figura. 4A. Al utilizar el medio de transporte donado por la casa comercial no se observó presencia de $\mathrm{ADN}$, datos que fueron confirmados, Figura 4B.

\section{Determinación de Beta globina en la muestras de hisopado anorrectal}

La optimización para la amplificación de B-globina se muestra en la figura 5 . El control positivo amplifico un segmento de $230 \mathrm{pb}$, utilizando los primer GH20 y PCO4 como se muestra en la figura 5A-carril 2. Sin embargo, la muestra de hisopado anorrectal extraída con el kit de la casa comercial Promega amplificó el fragmento de $230 \mathrm{pb}$ pero con un background como se observa en la figura 5A-carril 3. La muestra extraída con el kit de Epicentre no mostró banda de amplificación, 


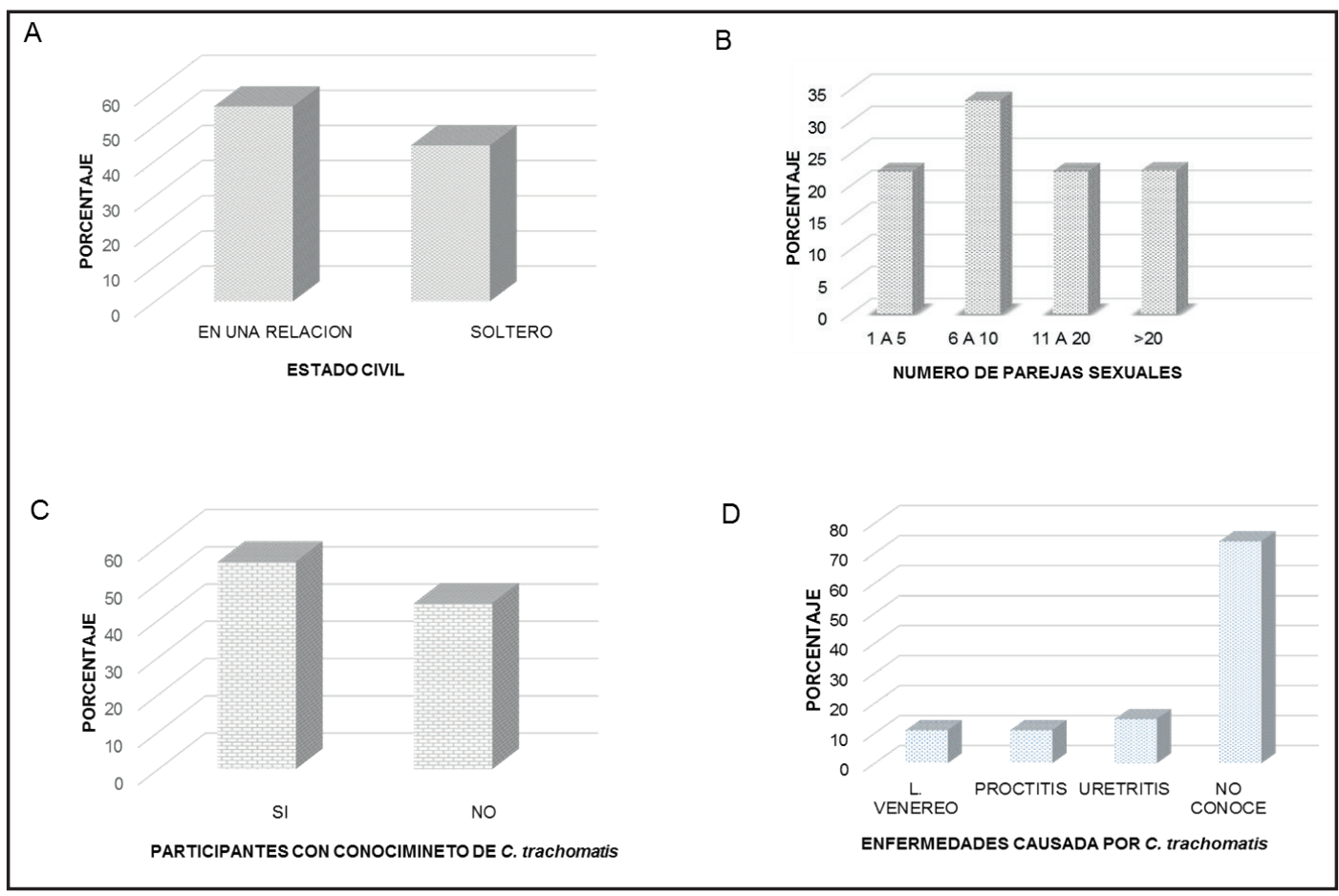

Figura 2. Determinantes de riesgo asociado al comportamiento sexual. A. Estado civil de los participantes. B. Porcentaje de parejas sexuales de los participantes al momento de realizar la encuesta. C. Porcentaje de participantes que tienen conocimiento acerca de C. trachomatis. D. Porcentaje de HSH que conocen las enfermedades causadas por C. trachomatis.

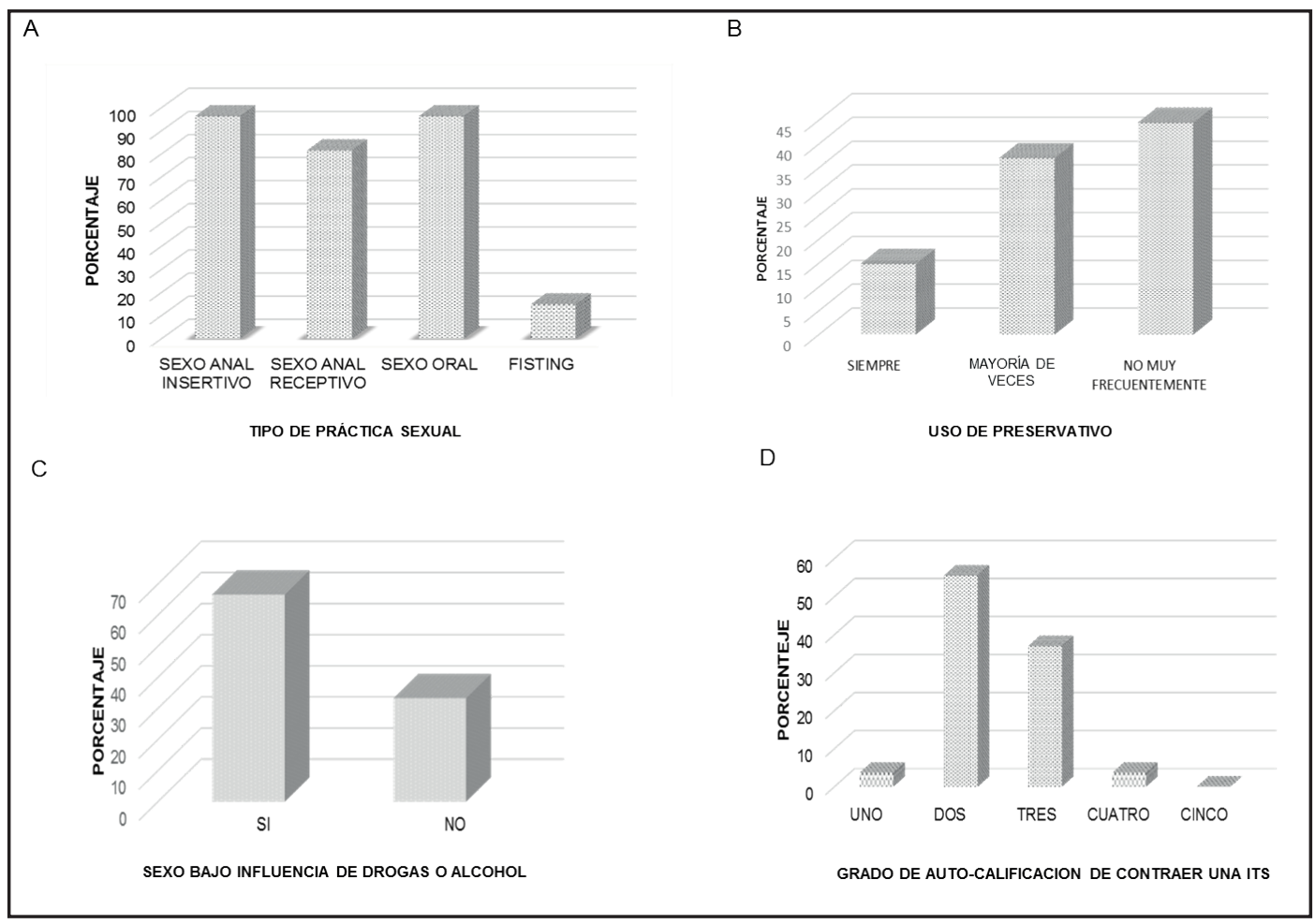

Figura 3. Riesgos asociados a las prácticas sexuales en la población de estudio: A. Porcentaje del tipo de relación sexual.

B. Frecuencia de uso de preservativo. C. Frecuencia de sexo practicado bajo influencia de sustancias psicoactivas. D. Auto calificación de los participantes de contraer una ITS uno como riesgo bajo y cinco como riesgo alto. 
por lo cual se descartó la utilización de este kit, figura 5A-carril 4. De las 27 muestras de hisopado anorrectal de los participantes, 19 mostraron una amplificación de 230pb, para la B-globina acompañada de un backgraund similar al que se presentó en la optimización, Figura 5B.
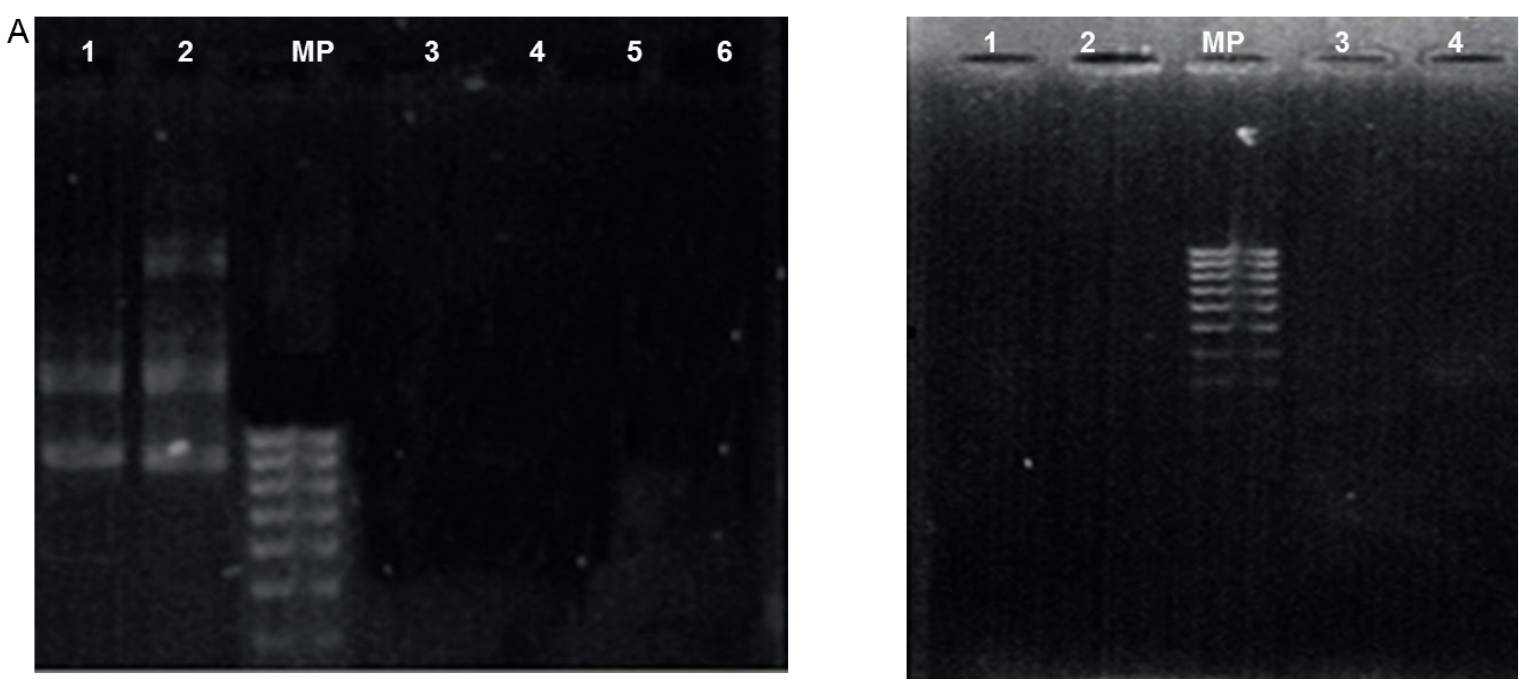

Figura 4. Optimización y extracción de ADN de muestras de hisopado anorectal: A. Carriles 1-2: PBS 1-X Kit Promega. Carril 3 -6 Medio de transporte Comercial y Kit Promega. B Carril 1-2 PBX1- Kit Epicentri. Carril 3-4 Medio de transporte commercial - Kit Epicentri.

A

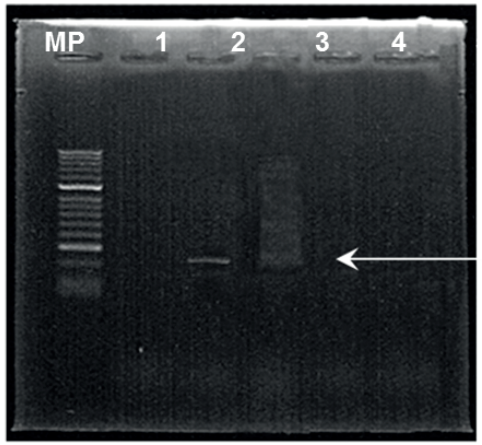

B

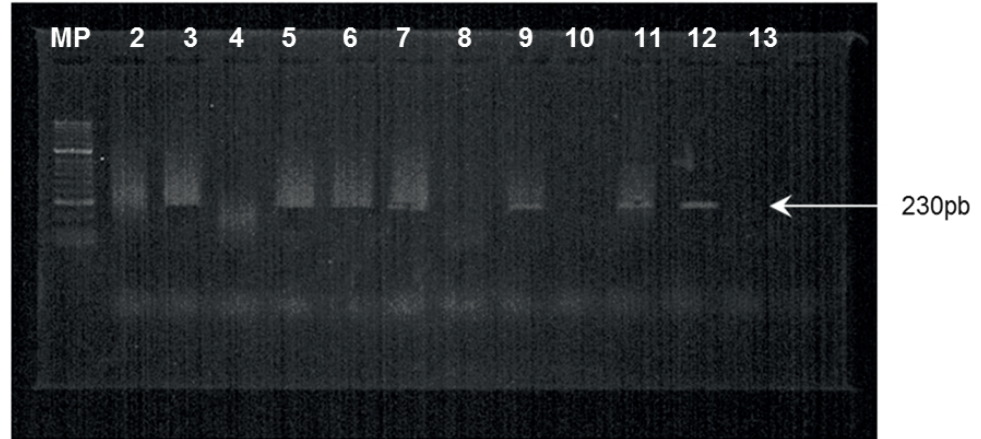

Figura 5. Detección de B-Globina mediante PCR. A Detección de B-globina. Carril 1: control negativo. Carril 2: control positivo ADN sangre total. Carril 3: muestra de hisopado anorrectal positiva para B-globina humana extraído con la casa comercial Promega. Carril 4: muestra de hisopado anorectal negativa para B-globina extraida con el kit de la casa comercial Epicentre. Carril 5: control negativo PCR. B. Corrido electroforético de 10 de las 27 muestras procesadas. Carril 1: marcador de peso molecular. Carriles 2, 4, 8, 10: muestras negativas para B-Globina. Carriles 3, 5, 6, 7, 9, 11: muestras positivas para B-Globina. Carril 12: control positivo. (ADN Sangre Humana). Carril 13: control negativo.

\section{Determinación de C. trachomatis}

La amplificación para determinar C. trachomatis se realizó con el control positivo donado por la FIDIC. Para los primers CTP1-2 se observó un fragmento $201 \mathrm{pb}$ y un fragmento de $310 \mathrm{pb}$ para los primers CTR1-2 como se observa en la figura 6A. Las muestras de los participantes se amplificaron con el set de primer CTP1-2, se encontraron 5 muestras positivas para C. trachomatis, Figura 6B.

\section{Evaluación de las muestras}

De las 27 muestras procesadas, el 18.5\% fueron positivas para $C$. trachomatis la determinación de B-globina como control interno para la calidad de las 
A

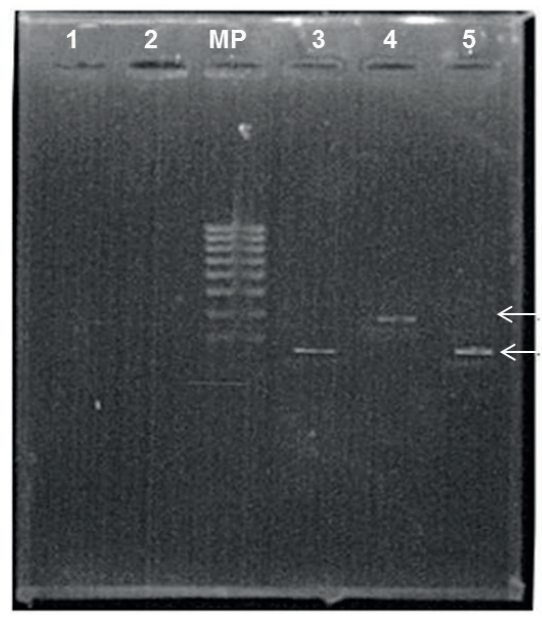

B

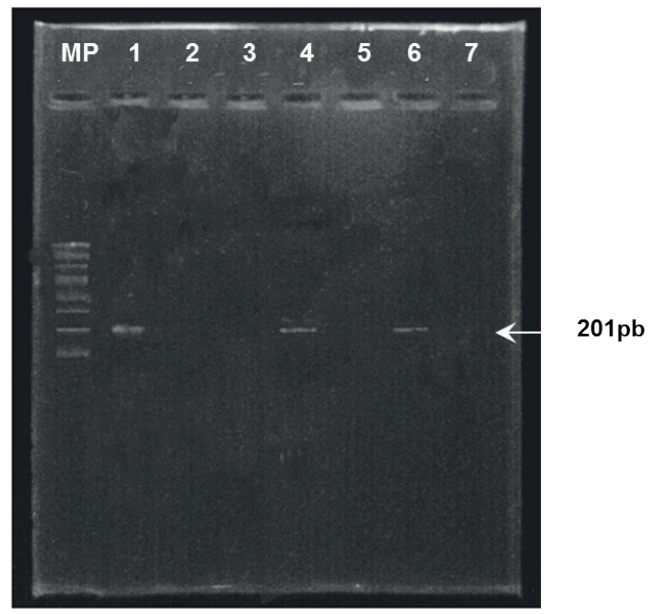

Figura 6. PCR para la detección de C. trachomatis: A. Detección de C. trachomatis con CtP1-2 y CtR1-2. Carril 1: control negativo para CtP1-2. Carril 2: control negativo para CtR1-2. Carril 3 y 5: set de primer CtP1-2 (201pb). Carril 4: set de primer CtR1-2 (310pb) B. Corrido electroforético de 5 de las 27 muestras procesadas utilizando set de primers CtP1-2. Carril 1: control positivo. Carril 2: control negativo. Carriles 3, 5, 7: muestras negativas. Carriles 4 y 6: muestras positivas.

muestras resultó eficiente encontrado que el $70.3 \%$ de las muestras de hisopado anorrectal amplificaron.
Sin embargo, a todas las muestras se les realizó la amplificación para C. trachomatis, Tabla 3.

Tabla 3. Detección de B-Globina y C. trachomatis en las 27 muestras sometidas a detección de $C$. trachomatis mediante PCR

\begin{tabular}{ccccc} 
& \multicolumn{4}{c}{ No. \% Muestras } \\
\cline { 2 - 5 } Tipo & $\begin{array}{c}\text { B-globina } \\
\text { Positiva }\end{array}$ & $\begin{array}{c}\text { B-globina } \\
\text { Negativa }\end{array}$ & $\begin{array}{c}\text { Presencia de C. } \\
\text { thachomatic }\end{array}$ & $\begin{array}{c}\text { Ausencia de C. } \\
\text { thachomatic }\end{array}$ \\
\hline $\begin{array}{c}\text { Hisopados } \\
\text { Anorrectales } \\
(\mathrm{n}=27)\end{array}$ & $19(70,3)$ & $8(29,6)$ & $5(18,5)$ & $22(81,4)$ \\
\hline
\end{tabular}

\section{Discusión}

En este estudio se realizó la optimización de la técnica de PCR que permitió la identificación de C. trachomatis a partir de hisopados anorrectales en HSH. Se evidenció que el tiempo de detección de la presencia o ausencia del microorganismo en la muestra fue significativamente más corto (3-4 horas) comparado con el método Gold standard de cultivo celular (4-5 días) (7-10).

En cuanto a los hábitos sexuales, se encontró una relación significativa entre la infección por C. trachomatis y la actividad sexual bajo el efecto de sustancias psicoactivas, iniciar una vida sexual a temprana edad, número de parejas sexuales y no usar preservativo. Estos datos coinciden con estudios realizados en jóvenes de Medellín y de Sabana de Cundinamarca (11-14).

El $81 \%$ de los participantes informaron haber tenido relaciones sexuales con personas infectadas con algunaITSy no tener conocimiento acerca de $C$. trachomatis o las posibles patologías que causa. Esto reafirma lo planteado por Lengen y colaboradores en Estados Unidos (15) quienes compararon la relación existente entre el conocimiento y el comportamiento sexual de jóvenes entre 16 y 24 ańos. Estos investigadores rescatan la importancia del concepto de prevención en la población 
juvenil frente a las ITS, especialmente la causada por $C$. trachomatis, que es considerada la infección bacteriana más prevalente a nivel mundial en tres aspectos fundamentales: conocimiento, educación y conducta sexual. Además, recomiendan ser trabajados en conjunto y desde temprana edad ya que permiten la unificación y concientización del concepto de prevención $(16,17)$.

La optimización de la extracción de $\mathrm{ADN}$ de los hisopados anorrectales con el kit de la casa comercial Promega, permitió obtener una mayor cantidad de ADN visualizado en el corrido electroforético. Estos datos son similares con lo establecido en la literatura donde se reporta extracción automatizada de $\mathrm{ADN}$ en este tipo de muestras, obteniendo una alta tasa de recuperación del material genético $(5,18,19)$.

La amplificación del gen de la B-globina permitió evaluar la calidad de las muestras tomadas por los participantes. La amplificación de B-globina ha sido utilizada a nivel molecular para evaluar la calidad y celularidad de las muestras por la presencia de ADN genómico (20). Por otro lado C. trachomatis presenta un ciclo de vida bifásico, encontrándose intracelular en algunos etapas del ciclo, por lo cual es necesario evaluar que las muestras obtenidas presenten una celularidad adecuada que permita detectar la presencia de este microorganismo tanto a nivel intracelular como extracelularmente (21). En estudios realizados en Europa y Canadá para la identificación de $C$. trachomatis en hisopados cervicales y uretrales antes de llevar a cabo la PCR a las muestras se les realiza amplificación para B-globina humana como control interno dentro del proceso para validar la efectividad de la extracción y el estado de la muestra (22).

Sin embargo, las muestras positivas para la amplificación de B-globina mostraron un background en el corrido electroforético. Esto se debe a las grandes cantidades de ADN bacteriano proveniente de enterobacterias que se encuentran en la flora gastrointestinal y al alto porcentaje de sales biliares que se eliminan en un $99 \%$ en las heces al ser insolubles. El estudió reportado por Monteiro y colaboradores en el cual se desarrolla una técnica de PCR para detección de $H$. pylori a partir de muestra de heces fecales, reporta la presencia de bandas electroforéticas con background similares a las obtenidas en este estudio. Ellos determinan que este background es debido a la presencia de polisacáridos complejos provenientes de materia vegetal propia de la dieta alimenticia (23).

En este estudio se realizó la amplificación de C. trachomatis a partir de $\mathrm{ADN}$ obtenido de hisopados anorrectales, utilizando el set de primers $\mathrm{CtP} 1$ y $\mathrm{CtP} 2$ que van dirigidos al plásmido críptico y amplifican un producto de $201 \mathrm{pb}$. La selección del set de primers para la $C$. trachomatis se realizó por el estudio realizado por Roosendal y colaboradores, quienes probaron 2 sets de primers (CtP1 y 2, y CtR1y2) para la detección de este patógeno en hisopados cervicales. CtR1y2 para el gen ARNr 16s. Sin embargo CtR1 y CtR2 amplifican para parte de $\mathrm{ARNr}$ de $C$. psittaci que los hace más inespecíficos al amplificar para más de una especie y con poca probabilidad de llegar a identificar en el 100\% C. trachomatis (24).

La detección de $C$. trachomatis en el grupo de $\mathrm{HSH}$ fue alta (5 casos) comparada con las 30 infecciones rectales reportada por el Instituto Nacional de Salud en el año 2011, en la población general sin diferenciar entre hombres y mujeres en Colombia (25). Otros estudios realizados en Perú demuestra que la prevalencia de $C$. trahomatis está dada en HSH jóvenes a partir de muestras de hisopado anorrectal y no en hisospados faríngeos, encontrado una prevalencia de $25 \%$ entre mujeres transexuales y HSH casados $(26,27,28)$.

Este es el primer estudio realizado en Colombia para determinar $C$. trachomatis en muestras de hisopado anorrectal de HSH utilizando PCR. Este estudio destaca la importancia de hacer diagnóstico de $C$. trachomatis en sitios extragenitales y en poblaciones vulnerables como 
lo son los HSH. Finalmente, es importante realizar campańas de concientización para que este grupo esté ampliamente informado sobre las consecuencias y complicaciones de las ITS en la salud sexual y reproductiva si no se las trata oportuna y apropiadamente.

\section{Conclusiones}

En este estudio se realizó la optimización de la extracción de $\mathrm{ADN}$ de hisopados anorrectales que permitieron la detección de $C$. trachomatis, procedimientos que pueden ser utilizados en el laboratorio clínico de rutina. Se encontró una alta frecuencia de factores inherentes a la exposición y comportamientos sexuales de riesgo relacionados con ITS.

Se determinó la presencia de $C$. trachomatis en el grupo de HSH. Por esta razón, se resalta la importancia de formular programas de prevención y protocolos que permitan prevenir y diagnosticar este microorganismo en el grupo de $\mathrm{HSH}$ con el fin de disminuir la propagación de esta ITS y poder intervenir los factores de riesgo.

\section{Agradecimientos}

$\mathrm{Al}$ personal de los grupos $\mathrm{VPH}$, receptores y biomol de la Fundación Instituto de Inmunología de Colombia (FIDIC), al Grupo de apoyo y estudio de la Diversidad Sexual (GAEDS) de la Universidad Nacional de Colombia por su participación en el proyecto.

\section{Referencias}

1. World Health Organization. Baseline report on global sexually transmitted infection surveillance 2012. WHO Libr. Cat. 2012;52.

2. Crickx E, Meignin V, Gérard L, Plantier-Colcher I. Rectal Lymphogranuloma Venereum in HIV-infected Patients Can Mimic Lymphoma. Journal of clinical gastroenterology, 2016; 50(5): 414-416.
3. Ortiz OL, Sánchez Mora RM. Chlamydia trachomatis: avances y perspectivas. Nova, 2003; 1(1): 14-27.

4. Coy G, Ostos OL, Pinzón J, Sánchez Mora, RM. Determinación de la asociación entre Chlamydia trachomatis y Neisseria gonorrhoeae, en muestras de orina mediante técnicas de biología molecular. Nova. 2004; 2(2): 28-32

5. Paredes M, Gómez Y, Torres M, Fernández M \& Tovar M. Prevalence of Chlamydia Trachomatis and Neisseria Gonorrhoeae in High School Students Between 14 and 19 Years-Old Using a Non Invasive Technique. Sexually Transmitted Infections. 2013; 8(1): A169-A169.

6. Martínez T, Angélica M. Diagnóstico microbiológico de las infecciones de transmisión sexual (ITS): Parte 1. ITS no virales. Revista chilena de infectología. 2009; 26(6): 529-539.

7. Carrera Páez LC, Pirajan Quintero ID, Urrea Suarez MC, Sánchez Mora RM, Gómez Jiménez M, Monroy Cano LA. Comparación del cultivo celular de HeLa y HEp2: Perspectivas de estudios con Chlamydia trachomatis. Nova.2015; 13(23):17-29.

8. Martin DH, Nsuami M, Schachter J, Hook EW, Ferrero D, Quinn TC. Use of multiple nucleic acid amplification tests to define the infected-patient "gold standard" in clinical trials of new diagnostic tests for Chlamydia trachomatis infections. Journal of clinical microbiology. 2004; 42(10): 4749-4758.

9. Jiang Y, Liu Y, Wang M, You C, Liu Q. Sensitivity of the Standard Chlamydia trachomatis Culture Method Is Improved After One Additional In Vitro Passage. Journal of clinical laboratory analysis. 2016.

10. Waaij DJ, Dubbink JH, Peters RP, Ouburg S \& Morré SA. Comparison of GMT presto assay and Roche cobas ${ }^{\oplus} 4800$ CT/NG assay for detection of Chlamydia trachomatis and Neisseria gonorrhoeae in dry swabs. Journal of microbiological methods. 2015; (118): 70-74.

11. Villegas A, Tamayo L. Prevalence of sexually transmitted infections, and risk factor for sexual health of adolescents, Medellín, Colombia 2013. Iatreia. 2016; 29(1): 5-17.

12. Tamayo L, López M, Villegas A, Arrubla M, Muñoz J. Determinantes de salud sexual e ITS en adolescentes rurales, escolarizados, Medellín Colombia 2011. Rev Salud Pública Medellin. 2011;(5):7-24.

13. Paredes MC, Gómez YM, Torres AM, Fernández M, Tovar MB. Prevalence of infections by Chlamydia trachomatis and Neisseria gonorrhoeae among high school students in the Sabana Central area of Cundinamarca, Colombia. Biomédica. 2015; 35(3): 314-324.

14. Occhionero M, Paniccia L, Pedersen D, Rossi G, Mazzucchini $\mathrm{H}$, Entrocassi A et al. Prevalencia de la infección por Chlamydia trachomatis y factores de riesgo de infecciones transmisibles sexualmente en estudiantes universitarios. Revista argentina de microbiología. 2015;47(1): 9-16.

15. Lengen $C$, Jäger $S$, Kistemann T. The knowledge, education and behaviour of young people with regard to Chlamydia trachomatis in Aarhus, Denmark and Bonn, Germany: do prevention concepts matter?. Soc Sci Med. 2010;70(11):1789-98.

16. Vivancos R, AbubakarI, Phillips Howard P, Hunter PR. School-based sex education is associated with reduced risky 
sexual behaviour and sexually transmitted infections in young adults. Public Health.2013; 127(1): 53-57.

17. Booth, AR, Norman P, Harris PR, Goyder E. Using the theory of planned behaviour and self-identity to explain chlamydia testing intentions in young people living in deprived areas. British journal of health psychology. 2014; 19(1): 101-112.

18. Peuchant O, Le Roy C, Herrmann B, Clerc M, Bébéar C, Barbeyrac B. MLVA subtyping of genovar E Chlamydia trachomatis individualizes the Swedish variant and anorectal isolates from men who have sex with men. PloS one. 2012; 7(2): 31-38.

19. Williams D, Churchill D. Ulcerative proctitis in men who have sex with men: an emerging outbreak. Bmj. 2006; 332(7533): 99-100.

20. Vaca Diana J. “ Identificacion Del Virus De Papiloma Humano Mediante Pcr-Rflp Y Posterior Genotipificacion En Muestras De Tejido Cervical Parafinado , Con Diagnóstico Histopatológico De Displasia Severa O Cáncer In Situ , Procedentes Del Hospital De Solca Núcleo Quito. Escuela Politécnica Del Ejército Departamento. 2012.

21. H Smith F, Tenover CW. Detection of Chlamydia trachomatis. in Diagnostic molecular microbiology. Am Soc Microbiol. 1993;37.

22. Markowicz M, Grilnberger E, Huber F, Leibl G, Abrahamian $\mathrm{H}$, Gartner $\mathrm{M}$, et al. Case report: lymphogranuloma venereum proctitis-from rapid screening to molecular confirmation of a masked sexually transmitted disease. El sevier. 2013; 76(4):516-7.
23. Monteiro L, Bonnemaison D, Vekris A, Petry KG, Bonnet J, Vidal R, et al. Complex polysaccharides as PCR inhibitors in feces: Helicobacter pylori model. J Clin Microbiol. 1997; 35(4): 995-998.

24. Roosendaal R, Walboomers JMM, Veltman, OR, Melgers I, Burger C, Bleker OP. Comparison of different primer sets for detection of Chlamydia trachomatis by the polymerase chain reaction. Journal of medical microbiology. 1993; 38(6):426-433

25. Ministerio de salud. Situación de las infecciones de transmisión sexual diferentes al VIH:2009-2011[internet] [consultado 2016 MAR 20]. Disponible en:https://www.minsalud.gov.co/ salud/Documents/observatorio_vih/documentos/monitoreo_ evaluacion/1_vigilancia_salud_publica/a_situacion_ epidimiologica/SITUACION\%20 DE\%20 LAS \% 20 INFECCIONES\%20DE\%20TRANSMISION1.pdf

26. Cáceres CF, Konda K, Segura ER, Lyerla R. HSH casados, que hacen sexo con mujeres, transgéneros y trabajadores sexuales. Sex Transm Infect.2008; (84):49-56.

27. Sanchez J, Lama JR, Kusunoki L, Manrique H, Goicochea P, Lucchetti et al. HIV-1, sexually transmitted infections, and sexual behavior trends among men who have sex with men in Lima, Peru. JAIDS Journal of Acquired Immune Deficiency Syndromes.2007; 4(5); 578-585.

28. Páez LCC, Quintero IDP, Suarez MCU, Mora RMS, Jiménez MG, Cano LAM. Comparación del cultivo celular de HeLa y HEp-2: Perspectivas de estudios con Chlamydia trachomatis. Nova. 2015;13(23). 